\title{
Occurrence of uterine carriers for Leptospira interrogans on slaughtered cows
}

\author{
Bruno Cabral Pires ${ }^{\mathrm{a}}$, Junia Berzin Grapiglia ${ }^{\mathrm{a}}$, Lio Moreira ${ }^{\mathrm{b}}$, Lauren Hubert Jaeger ${ }^{\mathrm{a}}$, \\ Filipe Anibal Carvalho-Costa ${ }^{c}$, Walter Lilenbaum ${ }^{\mathrm{a}, *}$ \\ ${ }^{a}$ Laboratory of Veterinary Bacteriology, Department of Microbiology and Parasitology, Universidade Federal Fluminense, Prof. Hernani Melo St., 101, São Domingos, \\ 24210-130 Niterói, RJ, Brazil \\ ${ }^{\mathrm{b}}$ Laboratory of Pathology, Department of Microbiology and Parasitology, Universidade Federal do Estado do Rio de Janeiro, Frei Caneca, 94, Centro, 20211-010 Rio de \\ Janeiro, RJ, Brazil \\ ${ }^{\mathrm{c}}$ Laboratory of Epidemiology and Molecular Sistematic, Fundação Oswaldo Cruz, Avenida Brasil, 4365, Manguinhos, 21040-360 Rio de Janeiro, RJ, Brazil
}

\section{A R T I C L E I N F O}

\section{Keywords:}

Leptospirosis

Genital tract

Uterus

$\operatorname{Sec} Y$

Sequencing

\begin{abstract}
A B S T R A C T
Reproductive tract is an important site of infection for chronic leptospirosis and cooperate in pathogenesis of reproductive failure, leading to economic losses. Since serology techniques cannot detect chronic carriers, the molecular analysis of clinical samples is an alternative to detect these animals on livestock. The aim of the present study was to perform a retrospective study in order to detect leptospiral uterine carriers in slaughtered cows. Tissue samples were collected from 50 post-pubertal, nonpregnant cows. These samples were fixed in $10 \%$ buffered formalin, paraffin-embedded and stored. PCR targeting lipL32 gene and molecular characterization by $\sec Y$ sequence was performed. Leptospiral DNA was identified in 18\% (9/50) examined blocks. Two sequences were characterized as $L$. interrogans. These findings suggest that the presence of infectious leptospires in uterus is associated with the physiopathogenesis of the reproductive failure.
\end{abstract}

Leptospirosis is an infectious disease that causes several reproductive disorders in cattle, including abortion and stillbirth [1]. Diagnosis by serology has several limitations, especially in detecting chronic infection. Thus, the disease may frequently go undetected in cattle [2].

Leptospires have been eventually detected in semen and vaginal fluid of ruminants, implying on potential venereal transmission [3-5]. Moreover, the bacterium has been cultured from aborted fetuses [6] as well as from the oviduct [7]. Nevertheless, despite its probable importance as an important extra-renal site of infection, few studies have addressed the identification of uterine carriers. Reports of bacterial isolation from the ruminant uterus are apparently limited to one study in non-pregnant cows [7] and another in ewes [8], and both cultured $L$. interrogans. There is one single study conducted on ruminants' uterine samples employing PCR on deer, but all samples resulted negative [9].

PCR has been conducted on formalin-fixed and paraffin-embedded samples (FFPE) to detect leptospiral DNA on human beings [10] and kidneys and lungs of slaughtered cattle [11,12]. To our knowledge, there are no reports of PCR regarding leptospiral detection on uterine bovine samples, neither fresh samples nor FFPE. In this context, the aim of the present study was to perform a retrospective study in FFPE samples in order to detect leptospiral uterine carriers in slaughtered cows.
This study was approved by ethics committee (\# 863). This is a retrospective study using samples $\left(0.5 \mathrm{~cm}^{3}\right)$ of the middle-third of the uterine horn collected from 50 post-pubertal, nonpregnant cows, at a local abattoir (near Rio de Janeiro, Brazil), between March/2003 and December/2004 [13]. Samples were fixed in 10\% buffered formalin, paraffin-embedded and stored since 2004. In the present study, these paraffin blocks were used in an attempt to detect DNA from pathogenic Leptospira sp.

DNA was extracted using DNeasy Blood \& Tissue Kit (Qiagen, California, EUA). Specific primers from the lipL32 gene, reported to be present only in pathogenic leptospires, were used for PCR reactions: lipL32-45 Forward (5'-AAGCATTACCGCTTGTGGTG-3') and lipL32-286 Reverse (5'-GAACTCCCATTTCAGCGATT-3'), amplifying a 242 bp fragment. The PCR reactions were done as described [14]. Molecular characterization of the amplicons was performed by sequencing the $\sec Y$ gene. Primers F (5'-ATG CCG ATC ATT TTT GCT TC-3') and R (5'CCG TCC CTT AAT TTT AGA CTT CTT C -3') were used for partial amplification of the $\sec Y$ gene as described [15]. PCR products were directly sequenced in both directions using Big Dye Terminator 3.1 cycle sequencing Kit (Life Technologies, Foster City, USA) on ABI 3730 (Life Technologies, Carlsbad, CA, USA) in PDTIS/Fiocruz genomic platform RPT01A (IOC/Fiocruz). Bio Edit v.5.0.9 [16] and MEGA v.6 [17] were used for editing and sequence analysis. The similarity of the

\footnotetext{
* Corresponding author.

E-mail address: wlilenbaum@id.uff.br (W. Lilenbaum).
} 


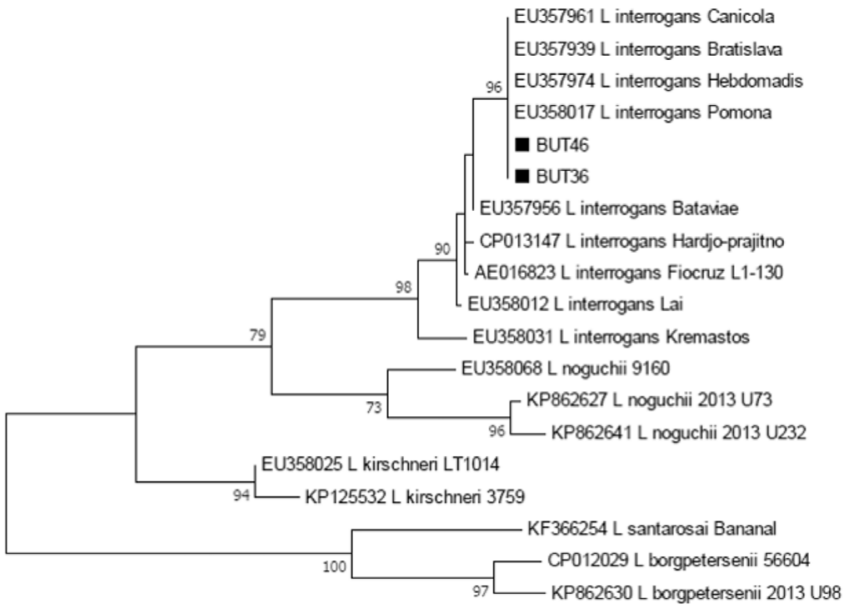

0.02

Fig. 1. Maximum likelihood tree inferred from Leptospira sp. partial secY gene. Black squares identify $L$. interrogans samples described in this study. Bootstrap values below $70 \%$ are not show.

sequences was obtained using the Basic Local Alignment Search Tool (BLAST - National Center for Biotechnology Information - EUA). Maximum likelihood (ML) genetic tree of partial $\sec Y$ gene was constructed in MEGA v.7.0.20 [18] using Kimura-2 parameters (K2P) model (bootstrap of 1000 replicates). The $\sec Y$ sequences available in GenBank comprising the members of the infectious Leptospira were used.

Leptospiral DNA from pathogenic Leptospira sp. could be amplified in nine out of the $50(18 \%)$ examined blocks. From those nine amplicons, two yielded good DNA sequences and were characterized by partial secY gene sequence (BUT36 and BUT46). Both demonstrated $100 \%$ of similarity with $L$. interrogans and the ML tree (Fig. 1 ) showed clustered in monophyletic branch with L. interrogans (GenBank EU358017, EU357961, EU357939 and EU357974). The two obtained sequences were deposited in GenBank database under accession numbers MF187958-MF187959.

Bovine leptospirosis in its chronic form is characterized by reproductive failure, mainly abortions, stillbirth and estrus repetition $[1,19]$. Strains of Leptospira sp. have been sporadically detected in the reproductive tract of various hosts, including mares [20], ewes $[3,8]$, female dogs [21], and cows [7].

Given its huge importance and impacts, it is surprising that literature on uterine infection is so scarce, particularly when compared to knowledge about renal infection. Serology presents disadvantages in detecting carriers, and molecular tests are required [14]. Culturing and/or DNA identification of leptospires from the reproductive tract represents a major challenge in the understanding of genital leptospirosis, probably due to the difficulty on obtaining in vivo samples. In this context, a recent study suggested vaginal fluid as an interesting sample in order to study bovine genital leptospirosis, with promising results [22].

Moreover, it is known that the use of preservatives can cause DNA damage (DNA crosslinks by formaldehyde) and impair experiments in molecular biology, including PCR [12]. Even though, it was possible to detect specific anti-leptospiral DNA on paraffin-embedded samples that were kept for 13 years. Therefore, it is possible that the real number of positive samples was higher than the observed.

Although effects and duration of leptospiral infection on the bovine uterus are not well understood, in experimentally infected female dogs it has been demonstrated that Leptospira interrogans damaged the endometrium, inciting an inflammatory response and abnormal expression of extracellular matrix proteins that could lead to disruption of embryo development and cause reproductive failure [21]. Detecting leptospiral DNA in $18 \%$ of the uterine samples was remarkable, and they were confirmed as Leptospira interrogans. These results, combined with the previous culturing of $L$. interrogans strains on ruminants' uterus $[7,8]$ support the hypothesis that $L$. interrogans can infect uterine tissues in cows, leading to reproductive failure.

Moreover, venereal transmission female-to-male has been considered and leptospiral DNA was found on vaginal fluid of different hosts $[3,20,22]$. The outcomes of the present study reinforce that hypothesis.

It was possible to detect uterine carriers for Leptospira interrogans in slaughtered cows. These findings suggest that the presence of infectious leptospires in uterus is associated with the physiopathogenesis of the reproductive failure.

\section{Conflicts of interest}

None.

\section{Funding}

This research did not receive any specific grant from funding agencies in the public, commercial, or not-for-profit sectors.

\section{Acknowledgements}

We thank A.P. Loureiro, DVM, PhD (UFF) for assistance with comments that greatly improved the manuscript. WL is a CNPq and Faperj fellow.

\section{References}

[1] B. Adler, History of leptospirosis and, Leptospira (2015), http://dx.doi.org/10. 1007/978-3-662-45059-8 1.

[2] W. Lilenbaum, G. Martins, Leptospirosis in cattle: a challenging scenario for the understanding of the epidemiology, Transbound. Emerg. Dis. 61 (2014) 63-68, http://dx.doi.org/10.1111/tbed.12233.

[3] A. Director, B. Penna, C. Hamond, A.P. Loureiro, G. Martins, M.A. Medeiros, W. Lilenbaum, Isolation of Leptospira interrogans Hardjoprajitno from vaginal fluid of a clinically healthy ewe suggests potential for venereal transmission, J. Med. Microbiol. 63 (2014) 1234-1236, http://dx.doi.org/10.1099/jmm.0.065466-0.

[4] W.A. Ellis, J.G. Songer, J. Montgomery, J.A. Cassells, Prevalence of Leptospira in terrogans serovar Hardjo in the genital and urinary tracts of non pregnant cattle, Vet. Rec. 118 (1986) 11-13.

[5] W. Lilenbaum, R. Varges, F.Z. Brandão, A. Cortez, S.O. de Souza, P.E. Brandão, L.J. Richtzenhain, S.A. Vasconcellos, Detection of Leptospira spp. in semen and vaginal fluids of goats and sheep by polymerase chain reaction, Theriogenology 69 (2008) 837-842, http://dx.doi.org/10.1016/j.theriogenology.2007.10.027.

[6] W.A. Ellis, J.J. O'Brien, S.D. Neill, H.W. Ferguson, J. Hanna, Bovine leptospirosis: microbiological and serological findings in aborted fetuses, Vet. Rec. 110 (1982) 147-150, http://dx.doi.org/10.1136/vr.110.7.147.

[7] W.A. Ellis, A.B. Thiermann, Isolation of leptospires from the genital tracts of Iowa cows, Am. J. Vet. Res. 47 (1986) 1694-1696.

[8] Z. Arent, C. Frizzell, C. Gilmore, D. Mackie, W.A. Ellis, Isolation of Leptospires from genital tract of sheep, Vet. Rec. 173 (2013) 582 doi:vr.101969 [pii] \\10.1136/ vr.101969.

[9] S. Subharat, P.R. Wilson, C. Heuer, J.M. Collins-Emerson, Investigation of localisation of Leptospira spp. in uterine and fetal tissues of non-pregnant and pregnant farmed deer, N. Z. Vet. J. 58 (2010) 281-285, http://dx.doi.org/10.1080/ 00480169.2010.69755.

[10] V. Manu, S. Roy, A.R. DuttaRoy, S. Sharma, P. Vijayachari, V.K. Kataria, S.C. Seghal, PCR on formalin-fixed necropsy tissues to diagnose leptospirosis, Indian J. Med. Res. 129 (2009) 105-107.

[11] S. Azizi, R. Kheirandish, E. Rahimi, Comparison of polymerase chain reaction and Warthin-Starry techniques to detect Leptospira spp. in kidneys of slaughtered cattle, Onderstepoort J. Vet. Res. 81 (2014) 1-6, http://dx.doi.org/10.4102/ojvr.v81i1. 821.

[12] Y.Z. D'Andrea, R. Martinez, V. Alduina, C.F. Monteverde, M. Molina, Vitale, Comparison of two PCR methods for detection of Leptospira interrogans in formalinfixed and paraffin-embedded tissues, Mem. Inst. Oswaldo Cruz 107 (2012) 85-88 http://www.scopus.com/inward/record.url?eid =2-s2.0-84857081573\& partnerID $=40 \& \mathrm{md} 5=1 \mathrm{~b} 66 \mathrm{~d} 0 \mathrm{cbce} 86 \mathrm{cc} 83878608 \mathrm{~b} 40 \mathrm{fd} 8 \mathrm{c} 7 \mathrm{e} 1$

[13] L. Moreira, E.C.Q. Carvalho, M.C. Caldas-Bussiere, Aspectos histopatológicos da adenomiose em úteros bovinos nas diferentes fases do ciclo estral, Arq. Bras. Med. Vet. E Zootec. 59 (2007) 1097-1102, http://dx.doi.org/10.1590/S010209352007000500002.

[14] C. Hamond, G. Martins, A.P. Loureiro, C. Pestana, R. Lawson-Ferreira, 
M.A. Medeiros, W. Lilenbaum, Urinary PCR as an increasingly useful tool for an accurate diagnosis of leptospirosis in livestock, Vet. Res. Commun. 38 (2014) 81-85, http://dx.doi.org/10.1007/s11259-013-9582-x.

[15] N. Ahmed, S. Manjulata Devi, M. de los, Á. Valverde, P. Vijayachari,

R.S. Machang'u, W.A. Ellis, R.A. Harstkeerl, S.M. Devi, R.A. Hartskeerl,

M.D.L.Á. Valverde, R.S. Machang, M. de los, A. Valverde, R.S. Machangu,

Multilocus sequence typing method for identification and genotypic classification of pathogenic Leptospira species, Ann. Clin. Microbiol. Antimicrob. 23 (2006) 5-28, http://dx.doi.org/10.1186/1476-0711-5-28.

[16] T. Hall, BioEdit: a user-friendly biological sequence alignment editor and analysis program for Windows 95/98/NT, Nucleic Acids Symp. Ser. 41 (1999) 95-98 doi:citeulike-article-id:691774.

[17] K. Tamura, G. Stecher, D. Peterson, A. Filipski, S. Kumar, Molecular evolutionary genetics analysis version 6.0, Mol. Biol. Evol. 30 (2013) 2725-2729, http://dx.doi. org/10.1093/molbev/mst197.

[18] S. Kumar, G. Stecher, K. Tamura, MEGA7: molecular evolutionary genetics analysis version 7.0 for bigger datasets, Mol. Biol. Evol. 33 (2016) 1870-1874, http://dx. doi.org $/ 10.1093 / \mathrm{molbev} / \mathrm{msw} 054$.

[19] G. Martins, W. Lilenbaum, Control of bovine leptospirosis: aspects for consideration in a tropical environment, Res. Vet. Sci. 112 (2017) 156-160, http://dx.doi.org/10 1016/j.rvsc.2017.03.021.

[20] C. Hamond, C.P. Pestana, C.M. Rocha-de-Souza, L.E.R. Cunha, F.Z. Brandão, M.A. Medeiros, W. Lilenbaum, Presence of leptospires on genital tract of mares with reproductive problems, Vet. Microbiol. 179 (2015) 264-269, http://dx.doi.org/10 1016/j.vetmic.2015.06.014

[21] W. Wang, X. Gao, M. Guo, W. Zhang, X. Song, T. Wang, Z. Zhang, H. Jiang, Y. Cao, $\mathrm{N}$. Zhang, Leptospira interrogans induces uterine inflammatory responses and abnormal expression of extracellular matrix proteins in dogs, Microb. Pathog. 75 (2014) 1-6, http://dx.doi.org/10.1016/j.micpath.2014.07.011.

[22] A.P. Loureiro, C. Pestana, M.A. Medeiros, W. Lilenbaum, High frequency of leptospiral vaginal carriers among slaughtered cows, Anim. Reprod. Sci. 178 (2017) 50-54, http://dx.doi.org/10.1016/j.anireprosci.2017.01.008. 